\title{
Influence of particle size on reaction selectivity in cyclohexene hydrogenation and dehydrogenation over silica-supported monodisperse Pt particles
}

\author{
R. M. Rioux ${ }^{\dagger}$, B. B. Hsu ${ }^{\S}$, M. E. Grass, H. Song ${ }^{\ddagger}$, and G. A. Somorjai* \\ Department of Chemistry, University of California, Berkeley and Lawrence Berkeley National \\ Laboratory, Materials and Chemical Sciences Division, Berkeley, CA 94720
}

Running title: Influence of particle size on selectivity for $\mathrm{C}_{6} \mathrm{H}_{10}$ conversion Keywords: cyclohexene, hydrogenation, dehydrogenation, platinum, particle size, selectivity

Correspondences should be addressed to somorjai@berkeley.edu

${ }^{\dagger}$ Current address: Department of Chemical Engineering, Pennsylvania State University, University Park, PA 16802

${ }^{\S}$ Current address: Department of Chemistry, Massachusetts Institute of Technology, Cambridge, MA 02139

${ }^{\ddagger}$ Current address: Department of Chemistry and School of Molecular Science (BK21), Korea Advanced Institute of Science and Technology, Daejeon, 305-701, Korea 


\begin{abstract}
The role of particle size during the hydrogenation/dehydrogenation of cyclohexene (10 Torr $\mathrm{C}_{6} \mathrm{H}_{10}, 200-600$ Torr $\mathrm{H}_{2}$, and $273-650 \mathrm{~K}$ ) was studied over a series of monodisperse Pt/SBA-15 catalysts. The conversion of cyclohexene in the presence of excess $\mathrm{H}_{2}\left(\mathrm{H}_{2}: \mathrm{C}_{6} \mathrm{H}_{10}\right.$ ratio $\left.=20-60\right)$ is characterized by three regimes: hydrogenation of cyclohexene to cyclohexane at low temperature $(<423 \mathrm{~K})$, an intermediate temperature range in which both hydrogenation and dehydrogenation occur; and a high temperature regime in which the dehydrogenation of cyclohexene dominates (> $573 \mathrm{~K}$ ). The rate of both reactions demonstrated maxima with temperature, regardless of $\mathrm{Pt}$ particle size. For the hydrogenation of cyclohexene, a nonArrhenius temperature dependence (apparent negative activation energy) was observed. Hydrogenation is structure insensitive at low temperatures, and apparently structure sensitive in the non-Arrhenius regime; the origin of the particle-size dependent reactivity with temperature is attributed to a change in the coverage of reactive hydrogen. Small particles were more active for dehydrogenation and had lower apparent activation energies than large particles. The selectivity can be controlled by changing the particle size, which is attributed to the structure sensitivity of both reactions in the temperature regime where hydrogenation and dehydrogenation are catalyzed simultaneously.
\end{abstract}




\section{Introduction}

Considerable work has been conducted to demonstrate the effect of particle size on reaction activity [1]. Reactions whose rate varies with particle size are referred to as structure sensitive and those independent of particle size are termed structure insensitive [2]. The effect is often seen in the particle size range of $1-5 \mathrm{~nm}$, the region over which the fraction of surface sites with different coordination change most drastically. At particle sizes above $5 \mathrm{~nm}$, bulk crystal habits have developed and changes in particle size lead to little change in the average coordination number. Experimentally, the apparent sensitivity of a reaction to the structure of a catalyst is determined by measuring the rate of reaction over a series of catalysts with varying particle size (ideally with catalysts who particle size is monodisperse [3, 4]). To this end, we synthesized nearly monodisperse Pt nanoparticles (NPs) $(1.7-7.1 \mathrm{~nm})$ by solution-phase colloidal methods, incorporated them into mesoporous SBA-15 silica matrices and constructed structure (particle size) - activity relationships for the one product reactions, ethylene hydrogenation and ethane hydrogenolysis [3, 4]. In this manuscript, we utilize the same set of monodisperse Pt NPs supported on SBA-15 catalysts to correlate the influence of particle size on selectivity during the hydrogenation-dehydrogenation of cyclohexene.

The hydrogenation of cyclohexene to cyclohexane on supported nanoparticle catalysts at ambient temperature [5] is structure insensitive [6], similar to benzene hydrogenation on supported Pt catalysts [7]. The measurement of the rate of cyclohexene hydrogenation on Pt single crystals under high pressure conditions and ambient temperature confirms the structure insensitivity of the reaction $[8,9]$.

The dehydrogenation of cyclohexene to benzene is structure sensitive on close-packed Pt single crystal surfaces; dehydrogenation proceeds more rapidly on the $\mathrm{Pt}(100)$ crystal surface 
than on the $\operatorname{Pt}(111)$ crystal surface $[8,9]$. Two reaction intermediates have been observed spectroscopically on both single crystal surfaces. On $\operatorname{Pt}(100), 1,3$-cyclohexadiene (CHD) is observed, whereas on $\mathrm{Pt}(111)$, both the 1,3- and 1,4-CHD species dehydrogenate to form benzene. The structure sensitivity of cyclohexene dehydrogenation is explained by noting that there is both a fast and slow reaction pathway on $\operatorname{Pt}(111)$; the slow 1,4-CHD pathway effectively eliminates surface sites for the faster 1,3-CHD pathway to turnover. The only pathway present on $\operatorname{Pt}(100)$ is through 1,3-CHD, where all active sites on $\operatorname{Pt}(100)$ participate in the fast reaction pathway [9].

Both hydrogenation and dehydrogenation products (cyclohexane and benzene) are thermodynamically-allowed and formed over Pt catalysts at intermediate temperatures $(400 \leq \mathrm{T}$ $\leq 600 \mathrm{~K})$. Previous work on silica-supported Pt catalysts demonstrated cyclohexene and benzene are not formed with thermodynamic selectivity [10]. There has been little examination of the influence of surface structure (or particle size) on the selectivity of cyclohexene conversion in excess hydrogen over experimental conditions where the formation of both cyclohexane and benzene is thermodynamically permissible [10] because most experimental studies have focused on conditions where only hydrogenation occurs (low temperature) or conditions where only dehydrogenation $[6,11]$ occurs (high temperature) $[12,13]$.

Little is known about the structure sensitivity of reaction selectivity [14]. Selectivity can be altered by eliminating certain types of sites from the surface of nanoparticles. A convincing demonstration of the role of specific surface sites controlling selectivity in a catalytic reaction was demonstrated recently for the chemoselective hydrogenation of acrolein over supported gold nanoparticle catalysts $[15,16]$. For Au nanoparticle catalyzed acrolein hydrogenation, the edges of single-crystalline gold particles have been identified as the active sites for the preferred $\mathrm{C}=\mathrm{O}$ 
hydrogenation suggesting that the size (and/or shape) of the nanoparticle can influence reaction selectivity [16]. The activity (and therefore selectivity) to the unsaturated alcohol during the chemoselective hydrogenation of crotonaldehyde increased with increasing particle size [17].

Our previous approach to understand the influence of particle size on catalytic activity has been to synthesize transition metal nanoparticle SBA-15-supported catalysts in which the particle size is carefully controlled by solution-phase nanoparticle synthesis $[3,4,18]$. In this paper, we examine the effect of particle size on reaction selectivity for the conversion of cyclohexene in excess hydrogen. We demonstrate that in a regime where both cyclohexene and benzene form, the surface is depleted in hydrogen and the particle size influences reaction selectivity through a particle size dependent reactive hydrogen coverage [19]. The hydrogenation of cyclohexene is structure insensitive under conditions of reversible hydrogen adsorption (low temperature) and becomes structure sensitive with an apparent dependence on hydrogen pressure which is much greater than unity at higher temperatures. We compare our results with kinetic measurements on platinum single crystals, which confirm the structure sensitivity of selectivity in cyclohexene hydrogenation-dehydrogenation in excess hydrogen [9].

\section{Experimental}

\subsection{Catalyst Synthesis and Characterization}

A series of $\sim 0.6 \% \operatorname{Pt}(X) / \mathrm{SBA}-15(X=1.7,2.9,3.6$ and $7.1 \mathrm{~nm})$ catalysts were used in these experiments. A detailed description of their synthesis and characterization has been published previously [3, 4]. Pt nanoparticles between 1.7 and $7.1 \mathrm{~nm}$ protected by polyvinylpyrrolidone (PVP) are synthesized by modified alcohol reduction methods to yield nearly monodisperse Pt nanoparticles. After synthesis of the nanoparticles, we encapsulated them in a SBA-15-like structure by direct participation in the hydrothermal process for mesoporous silica formation. 
The synthesis of SBA-15 is conducted at neutral $\mathrm{pH}$ using $\mathrm{NaF}$ as a catalyst for hydrolysis of the silica precursor [20], conditions which differ from the original description of SBA-15 synthesis [4]. Catalysts are activated ex-situ prior to catalysis by calcination in $20 \% \mathrm{O}_{2} / \mathrm{He}$ (or pure $\mathrm{O}_{2}$ ) and reduced in-situ directly before reaction in order to remove PVP fragments and adsorbed oxygen from the surface of the particle [4]. A $3.2 \% \mathrm{Pt} / \mathrm{SiO}_{2}$ catalyst prepared by ion-exchange of $\mathrm{Pt}\left(\mathrm{NH}_{3}\right)_{4}(\mathrm{OH})_{2} \bullet \mathrm{xH}_{2} \mathrm{O}$ at $\mathrm{pH} 9$ [21] was used as a standard sample for reaction studies. We reduced this catalyst (herein referred to as $\left.\operatorname{Pt}(1 \mathrm{~nm}) / \mathrm{SiO}_{2}\right)$ by an identical in-situ procedure used for the SBA-15 catalysts.

The characterization of these catalysts has been published previously $[3,4,22]$. The particle size determined by selective chemisorption $\left(\mathrm{H}_{2}-\mathrm{O}_{2}\right.$ titration) differed from the as-synthesized size measured for the unsupported clusters by $\mathrm{x}$-ray diffraction and transmission electron microscopy [3], which we believe is primarily due to the influence of residual PVP on the surface of the nanoparticle.

Kinetic measurements were conducted in a plug-flow reactor (PFR) operating under differential conditions (conversion varied between 1-20\%). Calcined Pt/SBA-15 catalysts (2-5 $\mathrm{mg}$ ) diluted in acid-washed low surface area quartz $(10-25 \mathrm{mg}$ ) were reduced in-situ (directly in the PFR) prior to reaction. Helium and $\mathrm{H}_{2}$ were delivered to the reactor with mass flow controllers (Unit Instruments Corporation, Model UFC 1200) while cyclohexene was pumped (typical volumetric flow rates were $1-10 \mathrm{~mL} \mathrm{~h}^{-1}$ ) into the $\mathrm{He} / \mathrm{H}_{2}$ flow by a syringe pump (Cole Parmer). All lines before and after the quartz U-tube reactor were heated to $393 \mathrm{~K}$ to prevent condensation of organic compounds. After allowing the catalyst to reach a steady-state activity at 273 or $298 \mathrm{~K}$, the catalyst bed was heated in ascending order (20 K increments) and cooled (first by $10 \mathrm{~K}$, and then in $20 \mathrm{~K}$ increments) back to room-temperature. There was no hysteresis 
in the temperature-dependent activity data suggesting that irreversible deactivation at high temperature was minimal. Reactant and product concentrations were measured during the ascending and descending temperature sequence with a gas chromatograph (Hewlett Packard 5890 Series II) equipped with a ten way-sampling valve allowing simultaneous monitoring of organics with a flame ionization detector (FID) and thermal conductivity detector (TCD) for detection of hydrogen. The mass activity $\left(\mu \mathrm{mol} \mathrm{g} \mathrm{g}^{-1}\right.$ ) for both cyclohexane and benzene were calculated from the measured chromatograph peak area using response factors [23] and assuming a rate equation for a differential reactor. The turnover frequency for both products was calculated by normalizing the mass activity $\left(\mu \mathrm{mol} \mathrm{g}{ }_{\text {cat }}^{-1} \mathrm{~s}^{-1}\right.$ ) to the number of surface Pt atoms $\left(\mathrm{Pt}_{\mathrm{s}}\right)$ determined by $\mathrm{H}_{2}-\mathrm{O}_{2}$ titration $[3,4]$.

\section{Results and Discussion}

\subsection{Influence of temperature on cyclohexene hydrogenation-dehydrogenation}

The temperature dependence of cyclohexene hydrogenation-dehydrogenation can be divided into three regimes (hydrogenation only, hydrogenation + dehydrogenation, and predominantly dehydrogenation) [24]. Hydrogenation is the only reaction at low temperatures ( $\leq 400 \mathrm{~K})$, while simultaneous hydrogenation and dehydrogenation occurs from $\sim 400$ to $600 \mathrm{~K}$ at standard conditions (10 Torr $\mathrm{C}_{6} \mathrm{H}_{10}, 200$ Torr $\mathrm{H}_{2}$, balance He). Dehydrogenation is the dominant reaction path at temperatures $\geq 600 \mathrm{~K}$. Figure 1 demonstrates that within the three regimes, the hydrogenation rate follows normal temperature dependent (Arrhenius) behavior, goes through a well-defined maximum $(\sim 350 \mathrm{~K})$ and then decreases with increasing temperature. The third regime is commonly referred to as 'non-Arrhenius' or 'bend-over' behavior [25] and has been reported for the hydrogenation of benzene on carbon-supported Fe and Pt catalysts [26, 27], the reforming of hexane in excess hydrogen on Pt catalysts [25, 28, 29], alkane hydrogenolysis [30, 
$31]$ and cyclohexene hydrogenation on $\operatorname{Pt}(111)$ and $\operatorname{Pt}(100)$ single crystal surfaces $[9,32,33]$. In the third regime $(\mathrm{T}>600 \mathrm{~K})$, the production of cyclohexane has decreased considerable (with turnover rates $\left(\sim 3 \mathrm{~s}^{-1}\right)$ comparable to those measured at $\left.300 \mathrm{~K}\right)$. The rate of dehydrogenation begins to decrease which is probably related to a decrease in cyclohexene and/or $\mathrm{H}_{2}$ coverage. Decreased activity at higher temperatures in not attributed to the deposition of carbon because during the decreasing temperature ramp, the measured rates fall in between the activity points measured during the ascending temperature ramp.

This non-Arrhenius behavior for the hydrogenation of cyclohexene leads to a negative apparent activation energy and is commonly associated with unfavorable adsorption thermodynamics leading to a low coverage of either $\mathrm{C}_{6} \mathrm{H}_{10}$ or $\mathrm{H}_{2}$, respectively. Yoon and Vannice noted a maximum turnover frequency at $\sim 473 \mathrm{~K}$ for $\mathrm{C}_{6} \mathrm{H}_{6}$ pressures (20-100 Torr), which decreased to $\sim 453 \mathrm{~K}$ at lower pressures ( $<3$ Torr) for $\mathrm{C}_{6} \mathrm{H}_{6}$ hydrogenation of over a supported-Fe catalyst. The increased benzene partial pressure affords a larger coverage of benzene. Yang and co-workers suggested recently that the 'bend-over' Arrhenius behavior for cyclohexene hydrogenation on $\operatorname{Pt}(111)$ was due to a low cyclohexene coverage [32]. Low hydrogen coverage has been proposed by others as the cause for non-Arrhenius behavior during hydrogenation reactions. Paál measured a maximum rate for hydrocarbon reforming reactions, and demonstrated it is related to a hydrogen coverage effect [25]. As the reaction temperature increases at constant hydrogen pressure, the hydrogen coverage and the rate of hydrocarbon reforming decreases. Paál suggested that measuring the rate maxima -- where the dependence on $\mathrm{H}_{2}$ is zero order -- as function of reaction temperature should yield a 'normal' apparent activation energy [25]. We examine the influence of hydrogen partial pressure on the non-Arrhenius behavior in section 3.4 . 
3.2 Temperature dependent structure sensitivity of cyclohexene hydrogenationdehydrogenation

The activity, turnover frequency (TOF), and apparent activation energy for both the hydrogenation and dehydrogenation of cyclohexene are compiled in Table 1. The rates for both reactions measured on a $\mathrm{Pt}(111)$ and $\mathrm{Pt}(100)$ single crystal are also included in Table 1 [9]. The hydrogenation TOF at $313 \mathrm{~K}$ is structure insensitive, the rates are $\sim 3.5 \mathrm{~s}^{-1}$ and the apparent activation energy is $\sim 9 \mathrm{kcal} \mathrm{mol}^{-1}$. Cyclohexene hydrogenation is structure-sensitive at low temperature, but as the temperature is increased into the 'non-Arrhenius' regime, the reaction becomes structure sensitive. Figure 2 demonstrates at $448 \mathrm{~K}$, the TOF on $\operatorname{Pt}(7.1 \mathrm{~nm}) / \mathrm{SBA}-15$ is a factor of four greater than the TOF on $\operatorname{Pt}(1.7 \mathrm{~nm}) / \mathrm{SBA}-15$. This difference is proposed to be due to a particle-size dependence on the total $\mathrm{H}_{2}$ coverage (i.e. a bare surface) or a decreased coverage of a particular population (subspecies) of adsorbed hydrogen (weak, moderately or strongly adsorbed hydrogen). We explore both of these scenarios by examination of published data on the measured differential heat of hydrogen adsorption $\left(\Delta \mathrm{H}_{\mathrm{ads}}(\theta=0)\right.$ dependence $)$ and temperature-programmed desorption (TPD) behavior of silica-supported Pt catalysts. Vannice and co-workers demonstrated there is no dependence of the initial heat of adsorption of $\mathrm{H}_{2}$ on the Pt particle size on $\mathrm{SiO}_{2}$-supported catalysts [34]; even though the heat of adsorption of hydrogen on single crystal surfaces is facet-dependent $[35,36]$. Based on the significant scatter in reported values for the integral (and differential) heats of adsorption of $\mathrm{H}_{2}$ at room temperature on silicasupported Pt catalysts, we propose that the heat of adsorption of a particular population of adsorbed hydrogen is particle-size dependent and represents the reactive hydrogen in the hydrogenation/dehydrogenation of cyclohexene. TPD of adsorbed hydrogen from $\mathrm{SiO}_{2-}$ supported Pt nanoparticles demonstrate that there can be up to three different populations of 
adsorbed hydrogen with desorption temperatures centered at $\sim 370 \mathrm{~K}, \sim 600 \mathrm{~K}$ and $~ 740 \mathrm{~K}$ [37]. The maximum temperature of desorption for the second desorption state (denoted as $\beta_{2}$ ) is particle size dependent. The desorption of $\mathrm{H}_{2}$ ranges from $410-440 \mathrm{~K}$ on small $(\sim 1 \mathrm{~nm})$ particles and $580-600 \mathrm{~K}$ for large $(5-15 \mathrm{~nm})$ particles; the $\beta_{2}$-hydrogen is most relevant hydrogen species during the hydrogenation of cyclohexene at temperatures greater than the rate maxima. The percentage of total hydrogen desorbed as a $\beta_{2}$ species from a series of silica-supported $\mathrm{Pt}$ catalysts (in general) increased with increasing particle size. The increased activity of the $\operatorname{Pt}(7.1$ $\mathrm{nm}) / \mathrm{SBA}-15$ for the hydrogenation of cyclohexene at the higher temperatures is supported by fact that the temperature for hydrogen desorption from the $\beta_{2}$ state increases with particle size. The particle-size dependent behavior of $\mathrm{H}_{2}$ TPD is consistent to explain the particle size dependence of cyclohexene hydrogenation at $448 \mathrm{~K}$ : the surface of large particles is covered with adsorbed hydrogen atoms, while $448 \mathrm{~K}$ is a temperature greater than the maximum desorption temperature of hydrogen for the small particles $(\sim 425 \mathrm{~K})$, resulting in a surface with decreased hydrogen coverage relative to the larger particles $(\sim 590 \mathrm{~K})$.

The kinetics for the dehydrogenation of cyclohexene at $423 \mathrm{~K}$ are reported in Table 1 . The TOF for dehydrogenation varies from $\sim 2-9 \mathrm{~s}^{-1}$ as the particle size increases from 1.7-7.1 $\mathrm{nm}$. The rate of dehydrogenation is more sensitive to particle size than hydrogenation. Over the 'normal' regime of Arrhenius behavior, the apparent activation energy varies from 16-24 kcal $\mathrm{mol}^{-1}$ (Figure 1B). At higher temperatures $(>550 \mathrm{~K})$, the rate of dehydrogenation leveled off for all particle sizes. In this regime, very small apparent activation energies $\left(\sim 2-3 \mathrm{kcal} \mathrm{mol}^{-1}\right)$ were measured. The decrease in rate is attributed to decrease in cyclohexene and/or $\mathrm{H}_{2}$ coverage [26, 32]. The dependence of the rate on the pressure of hydrogen is minor, and doesn't increase 
significantly with temperature $\left(\mathrm{H}_{2}\right.$ reaction order of 0.2 at $413 \mathrm{~K}$ compared with 0.3 at $\left.598 \mathrm{~K}\right)$ (see section 3.4).

Table 1 also includes the rates measured for cyclohexene hydrogenation and dehydrogenation at high pressure (760 Torr) on Pt single crystals. It is apparent from Table 1 that the rate of hydrogenation on the single crystal surfaces are on the same order as the Pt/SBA15 catalyst series, but the rate on $\operatorname{Pt}(111)$ is higher than the $\operatorname{Pt}(100)$ and $\operatorname{Pt}(223)$ surfaces at the reaction conditions (10 Torr $\mathrm{C}_{6} \mathrm{H}_{10}, 200$ Torr $\mathrm{H}_{2}$, and $313 \mathrm{~K}$ ) stated in Table 1. The rates of dehydrogenation are again higher on the $\operatorname{Pt}(111)$ surface than the $\operatorname{Pt}(100)$ or $\operatorname{Pt}(223)$ at the conditions specified in Table 1. The noticeable difference is the rate of dehydrogenation measured on the $\operatorname{Pt}(223)$; it is an order of magnitude lower than the $\operatorname{Pt}(1 \mathrm{~nm}) / \mathrm{SiO}_{2}$ catalyst, which presumably have similar surface structures. An explanation for the structure sensitivity on Pt single crystals has been suggested by McCrea and Somorjai based on characterization of the surface under reaction conditions by sum frequency generation (SFG) surface vibrational spectroscopy [9]. The (100) surface is more active (at temperature of rate maxima) than the (111) surface. A dehydrogenated intermediate, 1,3-cyclohexadiene has been identified on the $\operatorname{Pt}(100)$ surface, while two intermediates (1,3 and 1,4-cyclohexadienes) have been identified on the (111) surface by SFG. It is suggested that the 1,3-cyclohexadiene is the involved in a "fast" reaction pathway for benzene formation and the 1,4 species present only on the (111) surface converts to benzene at a much lower rate because the 1,4-CHD intermediate must intially isomerize to $1,3-\mathrm{CHD}$ before dehydrogenating to benzene. There is no spectroscopic evidence of either species on the surface of nanoparticles and therefore it is inappropriate to suggest the presence of one or both species on the nanoparticle surface during turnover explains the apparent structure sensitivity for benzene hydrogenation. 


\subsection{Role of particle size in cyclohexene hydrogenation-dehydrogenation selectivity}

The dehydrogenation of cyclohexene is more facile on the smaller particles, while hydrogenation is influenced by particle size in a temperature dependent manner (Figure 2). Figure 3 demonstrates the influence of particle size on the reaction selectivity at 10 Torr $\mathrm{C}_{6} \mathrm{H}_{10}$, 200 Torr $\mathrm{H}_{2}$ and $423 \mathrm{~K}$. The selectivity to benzene is highest (>60\%) on the $1 \mathrm{~nm}$ particles and subsequently decreases to less than $10 \%$ on large $(7.1 \mathrm{~nm})$ particles. This is a unique demonstration of the influence of particle size on reaction selectivity, and these conditions in particular demonstrate the major product can change with particle size. The inset demonstrates that the ability of a particle to change the major product is applicable only under certain experimental conditions. At $523 \mathrm{~K}$, the selectivity to benzene is $>60 \%$ for all particle sizes, although the selectivity to cyclohexane increases with particle size. The increase in selectivity to cyclohexane at larger particle size is significant and related to an increase in hydrogen coverage (see section 3.4).

The selectivity to hydrogenation-dehydrogenation products during cyclohexene conversion over a wide temperature range is also facet-dependent, as demonstrated by Somorjai and coworkers $[9,32,33]$. On $\mathrm{Pt}(100)$ at $423 \mathrm{~K}$, the selectivity to cyclohexane (10 Torr $\mathrm{C}_{6} \mathrm{H}_{10}, 100$ Torr $\mathrm{H}_{2}$ ) is $82 \%$, while the corresponding selectivity is $75 \%$ on $\mathrm{Pt}(111)$. At $523 \mathrm{~K}$, the higher selectivity to the hydrogenation product is now measured on the (111) surface ( 34\%), while the hydrogenation selectivity on $\operatorname{Pt}(100)$ is only $\sim 14 \%$ (see Figure 3 inset). Figure 3 demonstrates that the selectivity for both single crystal matches the $3 \mathrm{~nm}$ diameter particle, while the selectivity at $523 \mathrm{~K}$ demonstrate the (111) single crystal behaves more like the largest Pt particle, and the $\operatorname{Pt}(100)$ continues to behave like the $\operatorname{Pt}(2.9 \mathrm{~nm}) / \mathrm{SBA}-15$ catalyst. The nanoparticles used in this study do not demonstrate well-defined changes in shape with particle size; therefore, we 
believe the influence of particle size on reaction selectivity is related to changes in the average coordination number of the atoms within the nanoparticles rather than the shape of the nanoparticle.

\subsection{Influence of hydrogen pressure on cyclohexene hydrogenation-dehydrogenation activity and selectivity}

The influence of hydrogen partial pressure is shown in Figure 4 and 5 for the $\mathrm{Pt}(1 \mathrm{~nm}) / \mathrm{SiO}_{2}$ sample which we believe has the lowest coverage of hydrogen under reaction conditions [38]. As the pressure of hydrogen increases from 200 to 600 Torr, the dependence of the rate of the hydrogenation reaction changed considerable over a $400 \mathrm{~K}$ temperature interval. At low temperatures $(303 \mathrm{~K})$, the reaction order in $\mathrm{H}_{2}$ was 0.48 (see inset of Figure 4), which is in good agreement with previous measurements on supported Pt catalysts [11] and a Pt powder [6]. As the temperature increased, the reaction order became more positive, and approached values greater than unity. At $548 \mathrm{~K}$, the $\mathrm{H}_{2}$ reaction order for hydrogenation was $\sim 1.5$. A first-order dependence on hydrogen can be derived easily if the addition of a second hydrogen to the halfhydrogenated cyclohexyl $\left(\mathrm{C}_{6} \mathrm{H}_{11}\right)$ species is rate-determining, but there is no straightforward way based on Langmuir-Hinshelwood kinetic schemes to arrive at a $3 / 2$ order dependence on hydrogen. As the $\mathrm{H}_{2}$ pressure was doubled from 200 to 400 Torr, there was an increase in the temperature of maximum rate (from $\sim 350 \mathrm{~K}$ to $373 \mathrm{~K}$ ). The increase in rate over the entire temperature range suggests that the hydrogen content on the surface increases. Figure 5 demonstrates that the influence of increased hydrogen pressure is less dramatic for the dehydrogenation pathway. At low temperatures $(413 \mathrm{~K})$, the pressure dependence on $\mathrm{H}_{2}$ is 0.2 (inset of Figure 5). At a temperature of $598 \mathrm{~K}$, the dependence on $\mathrm{H}_{2}$ does not change substantially. This result is anticipated due to the fact that dehydrogenation only needs hydrogen 
to remove carbonaceous residues from the surface [25] and the weak dependence on hydrogen may suggest that most of the deposited carbon is mobile enough to migrate to the support without deactivating the catalyst [39]. In temperature-programmed reactions (both ascending and descending temperature ramps), we see no indication of high-temperature deactivation.

The increase in $\mathrm{H}_{2}$ pressure increased the selectivity to cyclohexane over the entire temperature range, but it is most apparent at high temperatures (non-Arrhenius behavior regime) where the steady-state coverage of hydrogen is affected to the greatest extent allowing for higher hydrogenation activity. Vannice and co-workers reported the integral heat of adsorption was invariant with particle size for a series of $\mathrm{SiO}_{2}$-supported $\mathrm{Pt}$ catalysts synthesized by standard impregnation methods [34]. An initial heat of adsorption measured on $\mathrm{Pt} / \mathrm{SiO}_{2}$ catalyst with an average particle size of $2 \mathrm{~nm}$ was $26.3 \mathrm{kcal} \mathrm{mol}^{-1}$ while the room temperature integral heat of adsorption at full monolayer coverage was $24.5 \mathrm{kcal} \mathrm{mol}^{-1}$ (these values were used for the Temkin isotherms calculated in Figure 4 as a function of temperature at two different $\mathrm{H}_{2}$ partial pressures). TPD studies by Sermon [37] on supported Pt catalysts demonstrate hydrogen requires a range of temperatures to fully desorb (apparent desorption energy, $\mathrm{E}_{d} \geq \Delta \mathrm{H}_{\mathrm{ads}}$; the apparent activation energy for desorption, $E_{a, d}>0$ ) due to the adsorption of different hydrogen populations on energetically non-equivalent sites, suggesting that the two reactions segregate on the surface ([10] and see Appendix I). Although the coverage determined by the Temkin plot calculates zero coverage at temperatures > $450 \mathrm{~K}$ (Figure 4), TPD studies demonstrate that hydrogen desorbs at temperatures $>600 \mathrm{~K}$, with the larger particles demonstrating more hightemperature hydrogen desorption [37]. We believe that this high-temperature population of adsorbed hydrogen increases with increasing hydrogen pressure (in a particle-size dependent 
manner) and is responsible for the increased hydrogenation activity with particle size at higher temperatures (Figure 4).

\section{Conclusions}

The role of Pt particle size $(1.7-7.1 \mathrm{~nm})$ on the selectivity to hydrogenation and dehydrogenation products during the conversion of cyclohexene in excess $\mathrm{H}_{2}$ was examined. The temperature dependence of the reaction is characterized by three regimes: hydrogenation only at low temperature $(\leq 400 \mathrm{~K})$; simultaneous hydrogenation and dehydrogenation at intermediate temperatures $(400 \leq \mathrm{T} \leq 550 \mathrm{~K})$, and predominantly dehydrogenation at high temperatures $(>550 \mathrm{~K})$. During simultaneous hydrogenation-dehydrogenation, the rate of hydrogenation decreases with increasing temperature (non-Arrhenius behavior), while benzene formation behaves in a normal Arrhenius manner. At high temperatures, where dehydrogenation dominates, the apparent activation energy remains positive but decreases substantially. The rate of dehydrogenation of cyclohexene to benzene decreases monotonically over the experimental particle size and the apparent activation energy decreases as the metallic dispersion increases. The activity for the hydrogenation of cyclohexene to cyclohexane is structure-insensitive under conditions of reversible $\mathrm{H}_{2}$ adsorption at low temperatures, but becomes structure sensitive at high temperatures due to a particle size dependence on the coverage of reactive hydrogen. The selectivity was particle size dependent in the pressure regime studied here $\left(\mathrm{H}_{2}: \mathrm{C}_{6} \mathrm{H}_{10}=20-60\right)$ due to a particle-size reactive hydrogen coverage dependence that causes the hydrogenation pathway to become structure sensitive at temperatures where the dehydrogenation of cyclohexene to benzene occurs simultaneously. This work demonstrates that under a particular set of reaction conditions, the selectivity during the conversion of cyclohexene can be influenced by particle size. 


\section{Acknowledgments}

This work was supported by the Director, Office of Science, Office of Advanced Scientific Computing Research, Office of Basic Energy Sciences, Chemical Sciences, Geosciences, and Biosciences Division, of the U.S. Department of Energy under Contract No. DE-AC0205CH11231. R.M.R. acknowledges the Ford Motor Company for financial support through a graduate fellowship administered by the Berkeley Catalysis Center. The authors acknowledge our long term collaboration with Professor Peidong Yang of the Department of Chemistry at the University of California, Berkeley. The authors would also like to acknowledge Professor M. A. Vannice of the Pennsylvania State University for donation of the $3.2 \% \mathrm{Pt} / \mathrm{SiO}_{2}$ material and $\mathrm{Dr}$. Samrat Mukherjee for its preparation.

\section{Appendix I. Deviations from thermodynamic selectivity at high temperatures: Influence of hydrogen coverage and surface reaction segregation}

The thermodynamics of cyclohexene hydrogenation are favored at low temperatures $\left(\Delta \mathrm{G}_{\mathrm{h}}=-\right.$ $18 \mathrm{kcal} \mathrm{mol}^{-1}$ at $\left.298 \mathrm{~K}\right)$, while the dehydrogenation is favored at high temperatures $\left(\Delta \mathrm{G}_{\mathrm{d}}=-11\right.$ $\mathrm{kcal} \mathrm{mol}^{-1}$ at $\left.600 \mathrm{~K}\right)$ [40]. The thermodynamic selectivity, defined as $\frac{K_{h}}{\left(K_{h}+K_{d}\right)}$, where $K_{h}$ and $K_{d}$ are the respective equilibrium constants (and related to the free-energy of reaction, $\left.K=\exp \left(\frac{-\Delta G_{h \text { or } d}}{R T}\right)\right)$ for hydrogenation and dehydrogenation is plotted as the solid line in Figure A1. The free-energy reaction data was obtained from [41]. At $400 \leq \mathrm{T} \leq 450 \mathrm{~K}$, the experimentally-measured selectivity for hydrogenation is lower than the thermodynamic selectivity for most samples, although a few of the low-temperature experimentally-measured selectivity data was greater than the thermodynamic value. This is attributed to error in the measurement of the individual reaction rates in this regime where the dehydrogenation activity is 
low. Figure A1-A demonstrates the selectivity for cyclohexane predicted by thermodynamics is much greater than the experimentally-measured values at temperatures $>450 \mathrm{~K}$ for all catalysts (supported and single crystal). The deviation in this temperature range is related to a much larger decrease in the rate of hydrogenation over this temperature range (see Figure 1A, the rate of hydrogenation actually decreases with increasing temperature) than the rate of dehydrogenation which has begun to plateau (Figure 1B). The overall trend of increased hydrogenation selectivity on catalysts containing larger particles is apparent over the entire temperature range as discussed in Section 3.2 and demonstrated in Figure 3. Due to the fact that cyclohexane selectivity is lower than the thermodynamic selectivity, the benzene selectivity will be correspondingly greater than the thermodynamic selectivity (Figure A1-B). For all but a few data points, the selectivity to benzene is greater than that predicted by thermodynamics.

Significant deviations of kinetic selectivity from thermodynamic selectivity has been documented previously for this reaction [10]. The authors suggested that both reactions surface segregate to specific sites on the nanoparticle surface [10]. Cyclohexene dehydrogenates preferentially at low coordination sites (which are more prevalent on smaller particles and consistent with particle-size dependent data (see Table 1)), and the adsorbed hydrogen diffuses away from low coordination sites to higher-coordination sites where it desorbs $\left(2 \mathrm{H}^{*} \rightleftharpoons \mathrm{H}_{2}(\mathrm{~g})+\right.$ $\left.2^{*}\right)$ immediately or reacts with cyclohexene adsorbed at high coordination sites to form cyclohexane. The hydrogen at the high coordination sites in the presence of adsorbed cyclohexane may represent the high temperature population observed in $\mathrm{H}_{2}$-TPD studies [37]. The equilibrium occurs in isolation, effectively separating adsorbed hydrogen and hydrocarbon, allowing non-equilibrium yields of benzene. Sermon and co-workers propose that under conditions where both cyclohexene hydrogenation and dehydrogenation occur on the same 
surface, the two reaction pathways segregate [10]. This picture is consistent with the cyclohexene hydrogenation rate and the observed changes in selectivity with particle size (see Figure 2 and 3, respectively).

\section{References}

1. M. Che, C. O. Bennett, Adv. Catal. 36 (1989) 55.

2. $\quad$ M. Boudart, Adv. Catal. 20 (1969) 153.

3. R. M. Rioux, H. Song, J. D. Hoefelmeyer, P. Yang, G. A. Somorjai, J. Phys. Chem. B 109 (2005) 2192.

4. H. Song, R. M. Rioux, J. D. Hoefelmeyer, R. Komor, K. Niesz, M. Grass, P. Yang, G. A. Somorjai, J. Am. Chem. Soc. 128 (2006) 3027.

5. The hydrogenation of cyclohexene at low temperatures is thermodynamically preferred, while dehydrogenation dominates at high temperature, and the switch between preferential hydrogenation and dehydrogenation occurs over a very narrow temperature range. Reaction temperatures of $400 \mathrm{~K}$ favor hydrogenation $\left(\mathrm{K}_{\mathrm{h}} / \mathrm{K}_{\mathrm{d}}=10^{7}\right)$, while $600 \mathrm{~K}$ favors dehydrogenation $\left(\mathrm{K}_{\mathrm{h}} / \mathrm{K}_{\mathrm{d}}=10^{-2}\right)$. .

6. $\quad$ E. Segal, R. J. Madon, M. Boudart, J. Catal. 52 (1978) 45.

7. T. A. Dorling, R. L. Moss, J. Catal. 5 (1966) 111.

8. S. M. Davis, G. A. Somorjai, J. Catal. 65 (1980) 78.

9. $\quad$ K. R. McCrea, G. A. Somorjai, J. Mol. Catal. A: Chem. 163 (2000) 43.

10. P. A. Sermon, G. Georgiades, M. M. A. Martin-Luengo, P. N., Proc. R. Soc. London, A 410 (1987) 353.

11. D. J. O'Rear, D. G. Löffler, M. Boudart, J. Catal. 94 (1985) 225.

12. J. M. Cogen, K. Ezaz-Nikpay, R. H. Fleming, S. M. Baumann, W. F. Maier, Angew. Chem. Int. Ed. Engl. 26 (1987) 1182.

13. É. Molnár, G. Tasi, Z. Kónya, I. Kiricsi, Catal. Lett. 101 (2005) 159.

14. F. Zaera, J. Phys. Chem. B 106 (2002) 4043.

15. C. Mohr, H. Hofmeister, P. Claus, J. Catal. 213 (2003) 86.

16. C. Mohr, H. Hofmeister, J. Radnik, P. Claus, J. Am. Chem. Soc. 125 (2003) 1905.

17. M. A. Vannice, B. Sen, J. Catal. 115 (1989) 65.

18. G. A. Somorjai, R. M. Rioux, Catal. Today 100 (2005) 201.

19. The influence of particle size on the coverage of hydrogen is complicated due to the presence of multiple hydrogen species on a Pt surface as demonstrated in temperature-programmed desorption (TPD) studies. If only a single population of adsorbed hydrogen is present on the surface, the effect is simply one of low surface coverage. However, if there are various populations of adsorbed hydrogen on the surface of the nanoparticle, the particle size dependence may be a result of the inability of one particle size to support a particular population (sub-species) of adsorbed hydrogen under reaction conditions.

20. J. M. Kim, Y. J. Han, B. F. Chmelka, G. D. Stucky, Chem. Commun. (2000) 2437.

21. U. K. Singh, M. A. Vannice, J. Catal. 191 (2000) 165.

22. R. M. Rioux, R. Komor, H. Song, J. D. Hoefelmeyer, M. Grass, K. Niesz, P. Yang, G. A. Somorjai, J. Catal. 254 (2008) 1.

23. W. A. Deitz, J. Gas Chromatogr. 5 (1967) 68.

24. A. Fási, I. Pálinkó, T. Katona, M. Bartók, J. Catal. 167 (1997) 215.

25. Z. Paál, J. Catal. 91 (1985) 181.

26. K. J. Yoon, M. A. Vannice, J. Catal. 82 (1983) 457.

27. J. M. Orozco, G. Webb, Appl. Catal. 6 (1983) 67.

28. A. Wootsch, Z. Paál, J. Catal. 185 (1999) 192.

29. A. Wootsch, Z. Paál, J. Catal. 205 (2002) 86. 
30. G. C. Bond, J. C. Slaa, Catal. Lett. 23 (1994) 293.

31. G. C. Bond, J. C. Slaa, J. Mol. Catal. A: Chem. 98 (1995) 81.

32. M. Yang, R. M. Rioux, G. A. Somorjai, J. Catal. 237 (2006) 255.

33. K. M. Bratlie, L. D. Flores, G. A. Somorjai, Surf. Sci. 599 (2005) 93.

34. B. Sen, M. A. Vannice, J. Catal. 130 (1991) 9.

35. R. W. McCabe, L. D. Schmidt, Surf. Sci. 60 (1976) 85.

36. R. W. McCabe, L. D. Schmidt, Surf. Sci. 65 (1977) 189.

37. M. S. W. Vong, P. A. Sermon, J. Chem. Soc., Faraday Trans. 83 (1987) 1369.

38. The entire Pt/SBA-15 series demonstrates an increase in rate (and a corresponding change in hydrogenation-dehydrogenation selectivity) with increasing hydrogen pressure. The dependence of the rate of hydrogenation was highly sensitive to the partial pressure of hydrogen over the $400 \mathrm{~K}$ interval shown in Figure 4.

39. J. M. Parera, N. S. Figoli, E. M. Traffano, J. N. Beltramini, E. E. Martinelli, Appl. Catal. 5 (1983)

33.

40. M. S. W. Vong, P. A. Sermon, J. Chem. Soc., Faraday Trans. 83 (1987) 1667.

41. G. J. Janz, J. Chem. Phys. (1954) 751. 
Table 1. The activity and selectivity for cyclohexene hydrogenation-dehydrogenation and the apparent activation energy (in the linear regime) over $\mathrm{SiO}_{2}$-supported Pt catalysts.

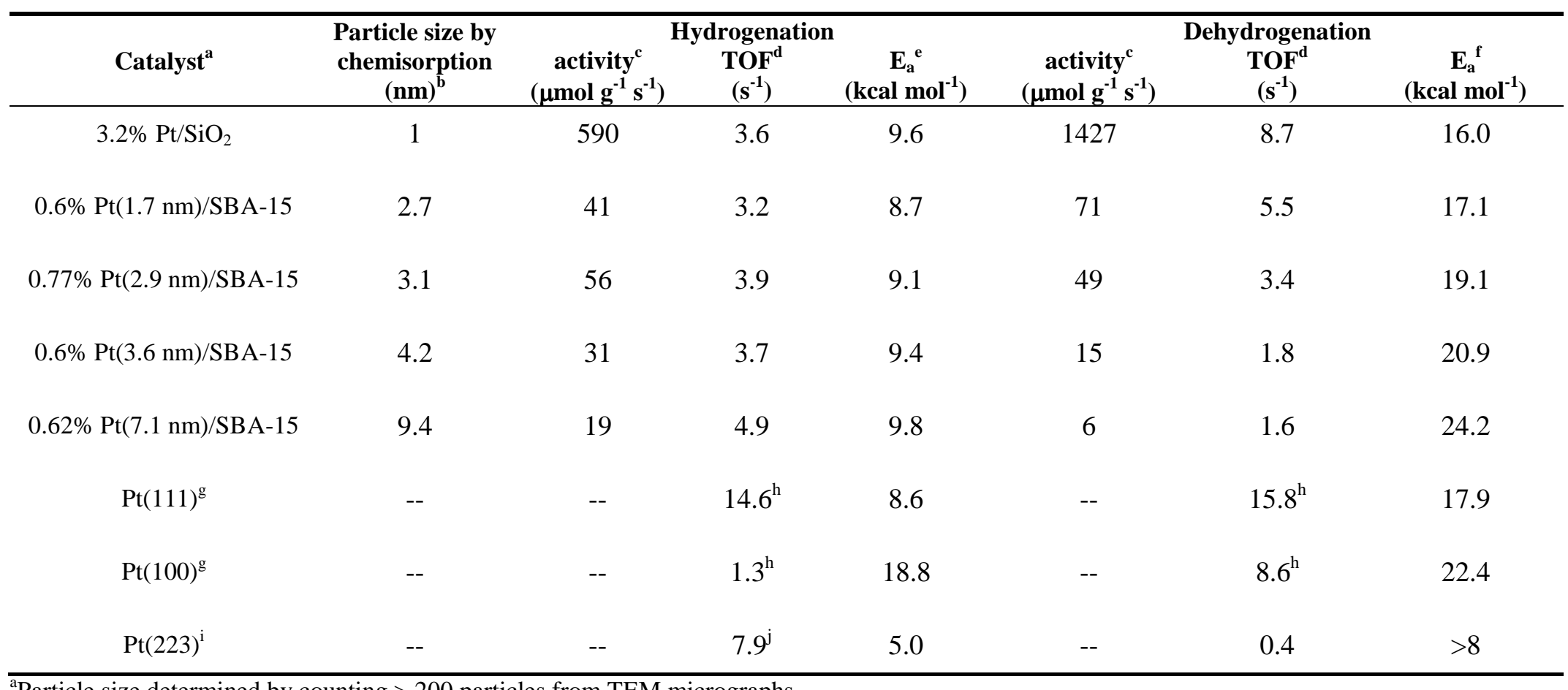

${ }^{\mathrm{a} P a r t i c l e ~ s i z e ~ d e t e r m i n e d ~ b y ~ c o u n t i n g ~}>200$ particles from TEM micrographs.

${ }^{b}$ Determined from the total $\mathrm{H}_{2}$ uptake after $\mathrm{O}_{2}$ chemisorption $\left(\mathrm{H}_{2}-\mathrm{O}_{2}\right.$ titration) and $\mathrm{d}(\mathrm{nm})=1.13 / D$, where $D$ is the dispersion.

${ }^{\mathrm{c}}$ Standard conditions are 10 Torr $\mathrm{C}_{6} \mathrm{H}_{10}, 200$ Torr $\mathrm{H}_{2}$, and $\mathbf{3 1 3} \mathbf{K}$ (hydrogenation) or $\mathbf{4 2 3} \mathbf{K}$ (dehydrogenation).

${ }^{\mathrm{d}}$ Normalized by the total number of surface atoms measured by $\mathrm{H}_{2}-\mathrm{O}_{2}$ titration.

eStandard conditions were 10 Torr $\mathrm{C}_{6} \mathrm{H}_{10}, 200$ Torr $\mathrm{H}_{2}$, and 273-323 K for the supported catalysts. The activity in this temperature regime displays 'normal' Arrhenius temperature-dependent behavior.

${ }^{\mathrm{f}}$ Standard conditions were 10 Torr $\mathrm{C}_{6} \mathrm{H}_{10}, 200$ Torr $\mathrm{H}_{2}$, and 398-443 K for the supported catalysts. The activity in this temperature regime displays 'normal' Arrhenius temperature-dependent behavior.

${ }^{\mathrm{g}}$ From reference [9].

${ }^{\mathrm{h}}$ The original reaction conditions were 10 Torr $\mathrm{C}_{6} \mathrm{H}_{10}, 100$ Torr $\mathrm{H}_{2}$, balance He and temperatures specified in (c). The rates were corrected to standard conditions assuming 0.75 order $\mathrm{H}_{2}$ dependence for hydrogenation [6] and 0.2 reaction order for dehydrogenation (this work).

${ }^{\mathrm{i}}$ From reference [8].

${ }^{\mathrm{j}}$ The original reaction conditions were 7 Torr $\mathrm{C}_{6} \mathrm{H}_{10}, 70$ Torr $\mathrm{H}_{2}$, balance He. The rates were corrected to standard conditions assuming 0.75 order $\mathrm{H}_{2}$ dependence for hydrogenation [6] and 0.2 reaction order for dehydrogenation (this work). 

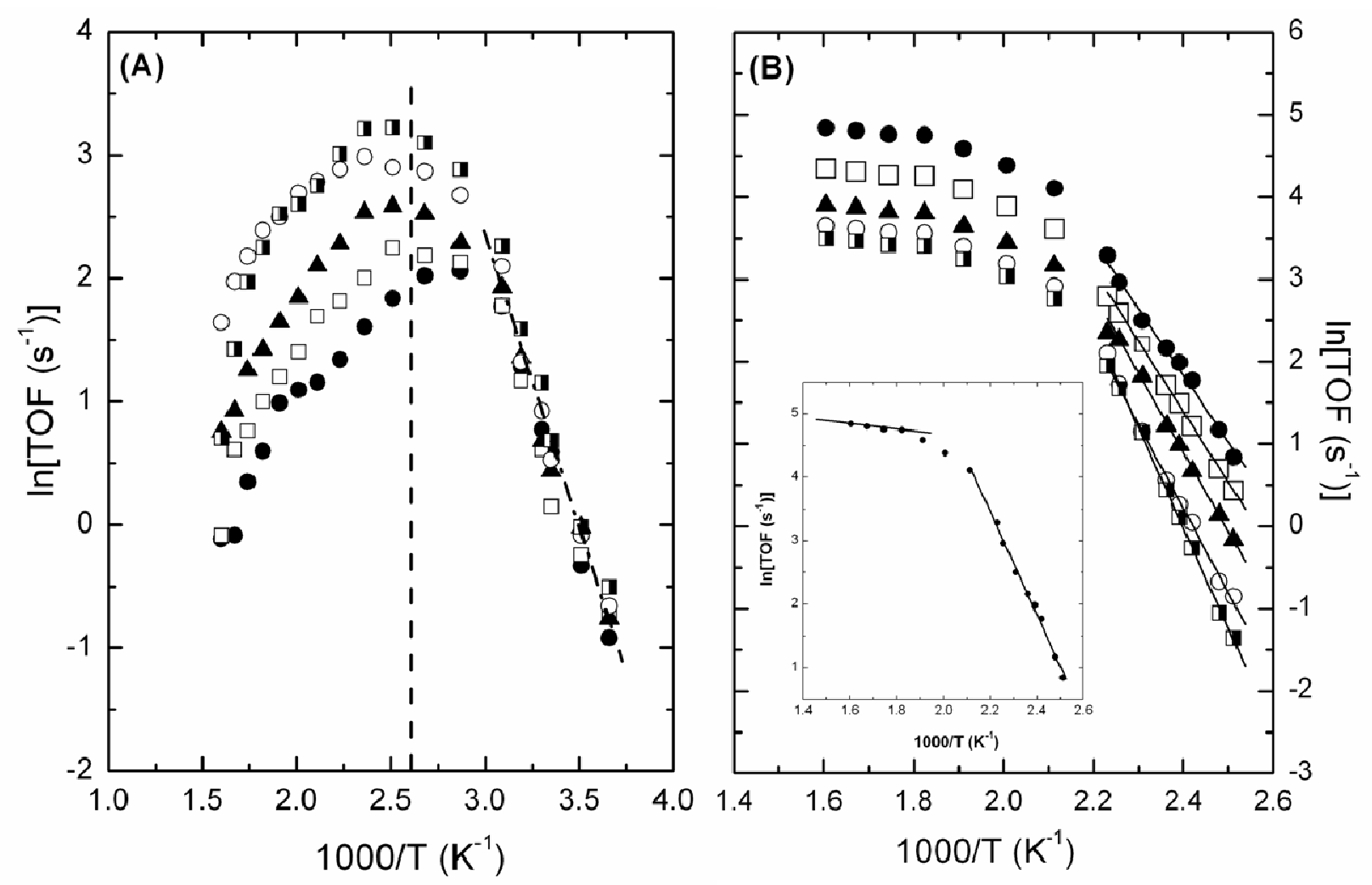

Figure 1. Arrhenius plots for cyclohexene (A) hydrogenation and (B) dehydrogenation on (,) $3.2 \% \mathrm{Pt}(1 \mathrm{~nm}) / \mathrm{SiO}_{2} ;(\forall) 0.6 \% \mathrm{Pt}(1.7 \mathrm{~nm}) / \mathrm{SBA}-15 ;(7) 0.77 \% \mathrm{Pt} /(2.9 \mathrm{~nm}) / \mathrm{SBA}-15 ;(-) 0.6 \%$ $\mathrm{Pt}(3.6 \mathrm{~nm}) / \mathrm{SBA}-15$; and ()) $0.62 \% \mathrm{Pt}(7.1 \mathrm{~nm}) / \mathrm{SBA}-15$. The Arrhenius plots for hydrogenation undergo a change in the sign of the slope (non-Arrhenius behavior) at a temperature of $\sim 350 \mathrm{~K}$ for all particle sizes. The Arrhenius plot for dehydrogenation demonstrates the rate begins to level off at a temperature of $\sim 550 \mathrm{~K}$. The inset of (B) shows that the slope at high temperature corresponds to an apparent activation energy $\left(\mathrm{E}_{\text {app }}\right)$ of $\sim 2 \mathrm{kcal} \mathrm{mol}^{-1}$, while the low temperature $\mathrm{E}_{a p p}$ (Arrhenius regime) is an order of magnitude larger for the $3.2 \% \mathrm{Pt}(1 \mathrm{~nm}) / \mathrm{SiO}_{2}$ catalyst. The rates were measured at 10 Torr $\mathrm{C}_{6} \mathrm{H}_{10}, 200$ Torr $\mathrm{H}_{2}$ and balance He. The dashed vertical line in (A) represents the temperature at which dehydrogenation activity is measured initially. 


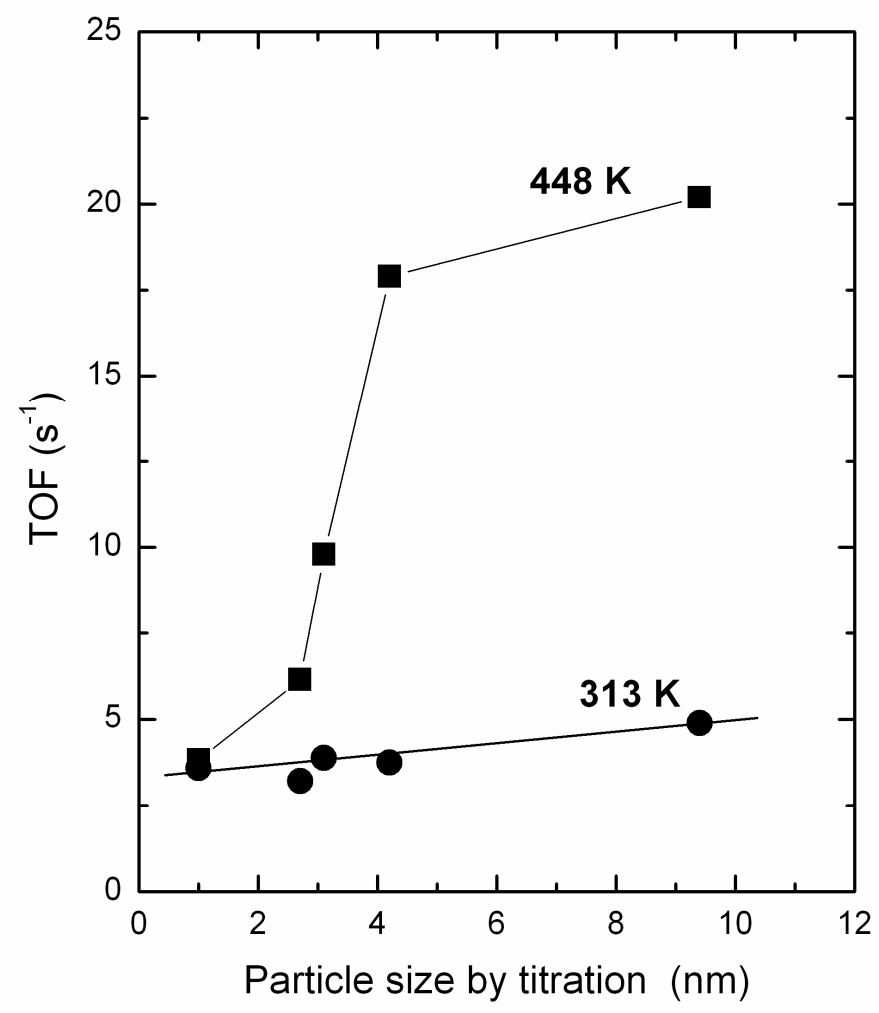

Figure 2. The influence of particle size on the turnover rate (normalized to the number of surface atoms determined by $\mathrm{H}_{2}-\mathrm{O}_{2}$ titration) for cyclohexene hydrogenation at two different temperatures (313 and $448 \mathrm{~K}$ ). The reaction is structure insensitive at low temperatures, and apparently structure sensitive at high temperatures. This difference in reactivity as a function of temperature and particle size is attributed to change in the coverage of reactive hydrogen. 


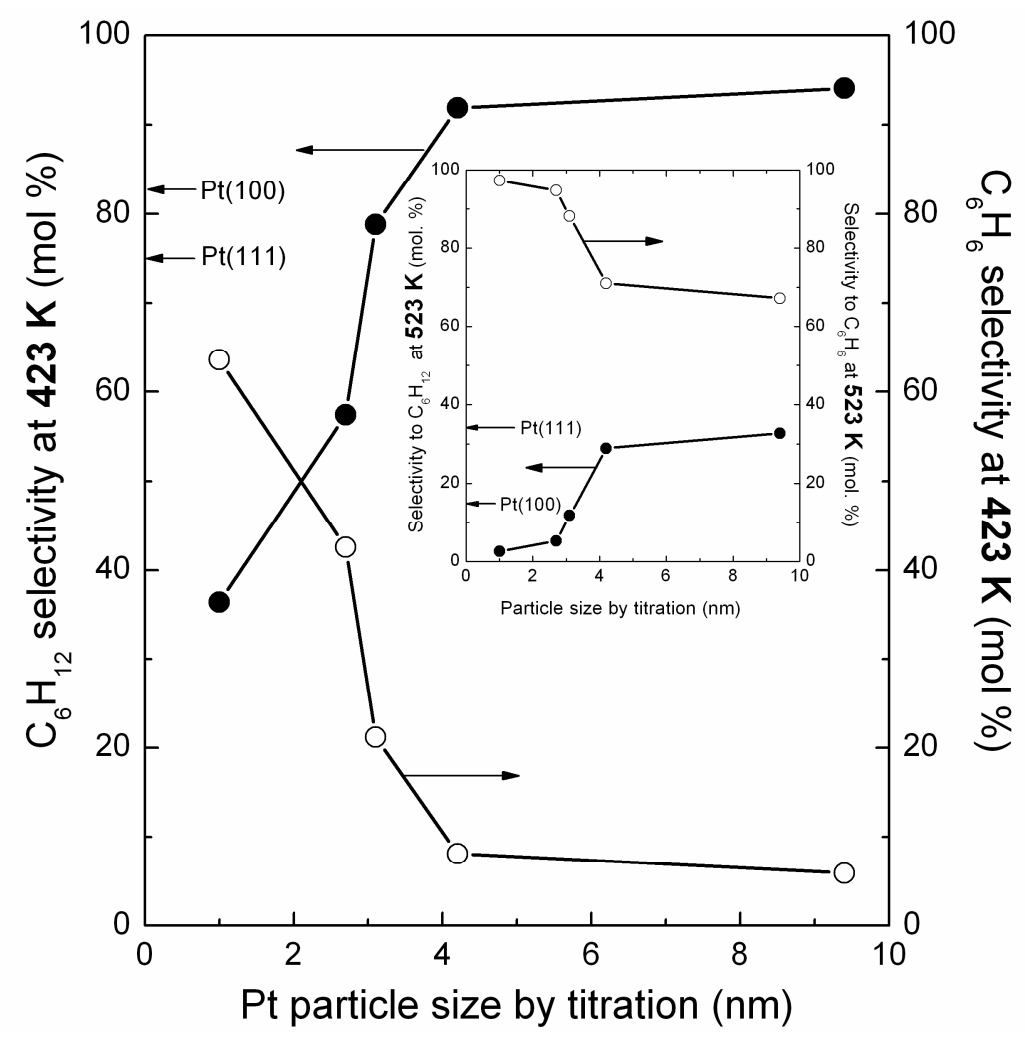

Figure 3. The influence of particle size on reaction selectivity during the hydrogenation/dehydrogenation of cyclohexene over the series of Pt/SBA-15 catalysts. The reaction conditions are 10 Torr $\mathrm{C}_{6} \mathrm{H}_{10}, 200$ Torr $\mathrm{H}_{2}$, and $423 \mathrm{~K}$. The inset is the selectivity at 523 $\mathrm{K}$ and the same pressure conditions. At $423 \mathrm{~K}$, the particle size dictates selectivity; $\operatorname{Pt}(1.7 \mathrm{~nm})$ is more selective for the formation of benzene than catalysts with the larger particle size. At higher temperatures, where dehydrogenation dominates, the particle size has a smaller influence on the selectivity to the minor product, cyclohexane. The hydrogenation selectivity is marked on the ordinate of the figure (and inset) for $\mathrm{Pt}(111)$ and $\mathrm{Pt}(100)$ single crystals [9]. 


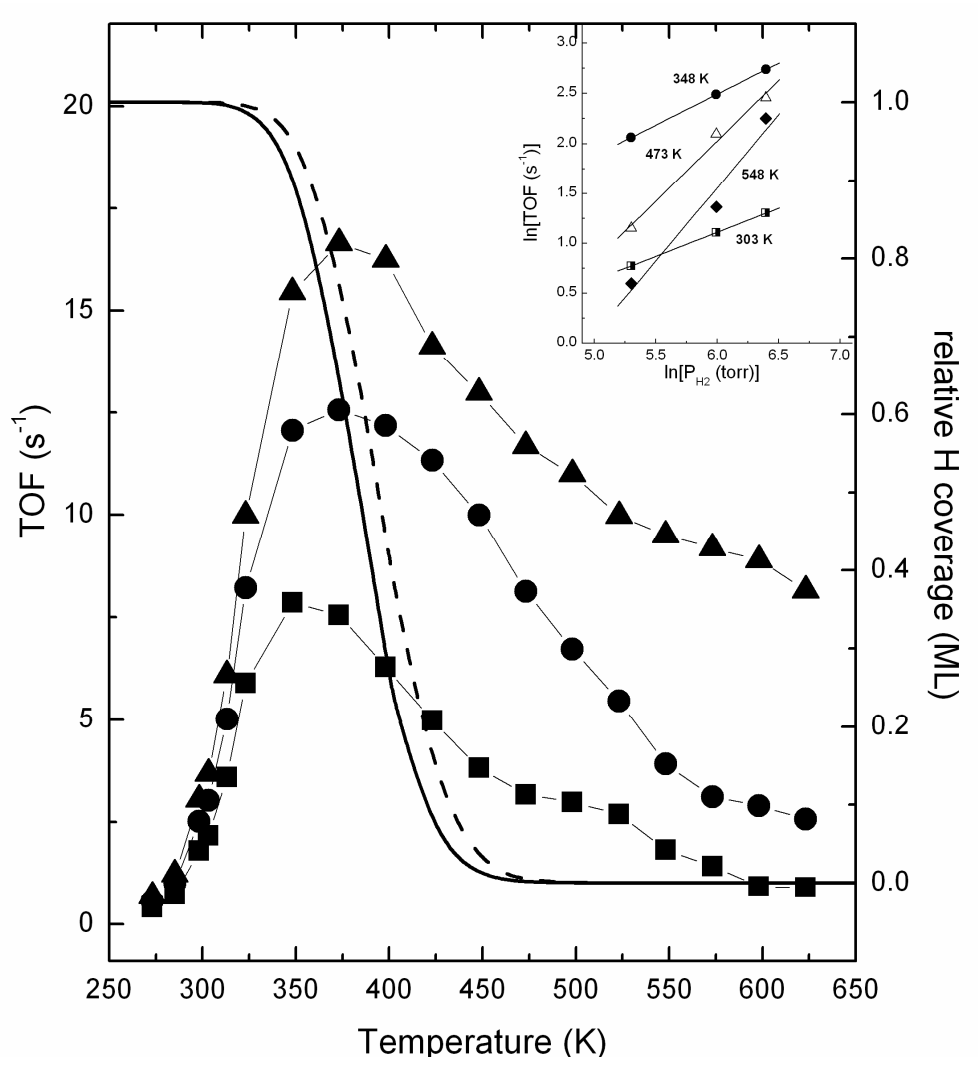

Figure 4. The influence of $\mathrm{H}_{2}$ pressure ((!) 200 Torr; (,) 400 Torr; and (7) 600 Torr) on the rate of cyclohexene hydrogenation on the $3.2 \% \mathrm{Pt}(1 \mathrm{~nm}) / \mathrm{SiO}_{2}$ catalysts over the entire temperature range (i.e. normal and non-Arrhenius region). The solid and dashed lines represent the calculation of hydrogen coverage using the initial and monolayer heat of adsorption values [34] in the Temkin isotherm for gas-phase hydrogen pressures of 200 and 600 Torr $\mathrm{H}_{2}$. The inset demonstrates the change in $\mathrm{H}_{2}$ reaction order with temperature. At low temperatures $(\sim 303 \mathrm{~K})$, the dependence of the reaction rate on the hydrogen pressure is $1 / 2$ order. The reaction order in $\mathrm{H}_{2}$ increases as the reaction temperature increases: $0.48(303 \mathrm{~K}) ; 0.61(348 \mathrm{~K}) ; 1.2(473 \mathrm{~K})$; and $1.47(548 \mathrm{~K})$. 


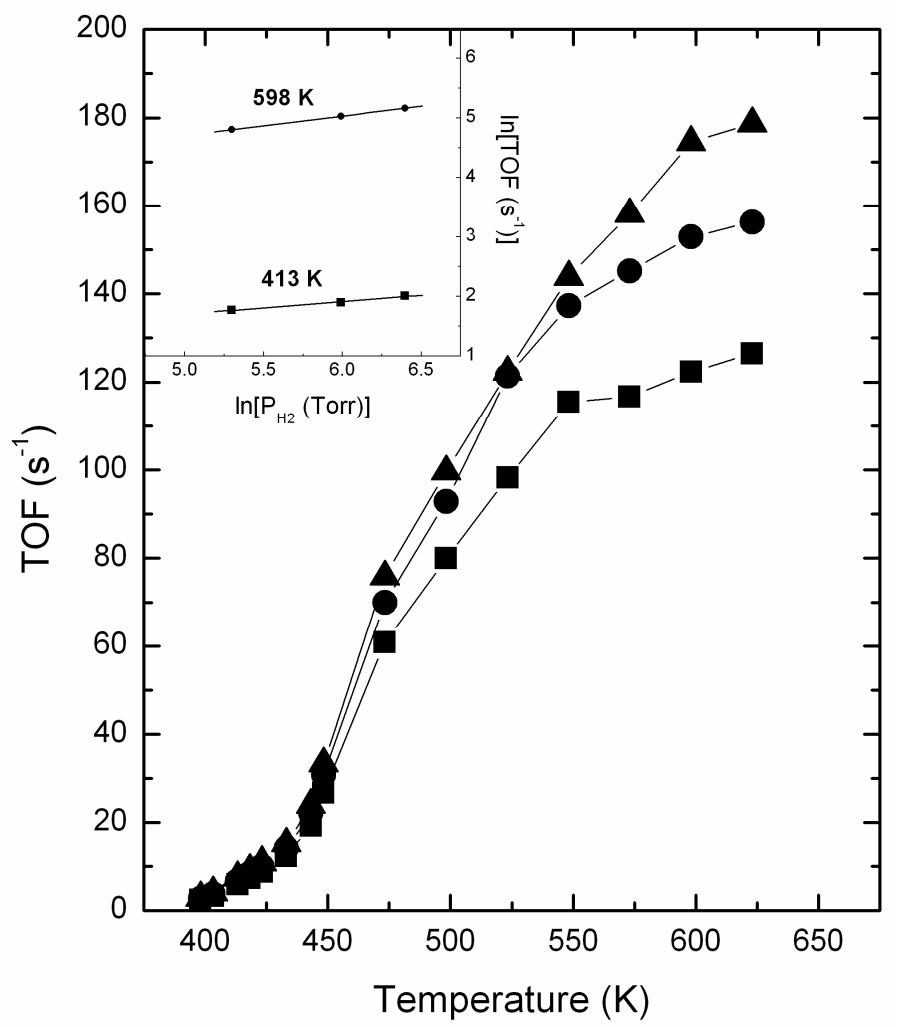

Figure 5. The influence of $\mathrm{H}_{2}$ pressure ((!) 200 Torr; (,) 400 Torr; and (7) 600 Torr) on the rate of cyclohexene dehydrogenation on the $3.2 \% \mathrm{Pt}(1 \mathrm{~nm}) / \mathrm{SiO}_{2}$ catalyst over the entire temperature range. The inset demonstrates the change in $\mathrm{H}_{2}$ reaction order with temperature. At $413 \mathrm{~K}$, the dependence on $\mathrm{H}_{2}$ is positive but low ( 0.2), and as the temperature increases the dependence on hydrogen increases only slightly (reaction order at $598 \mathrm{~K}$ is 0.3 ). 


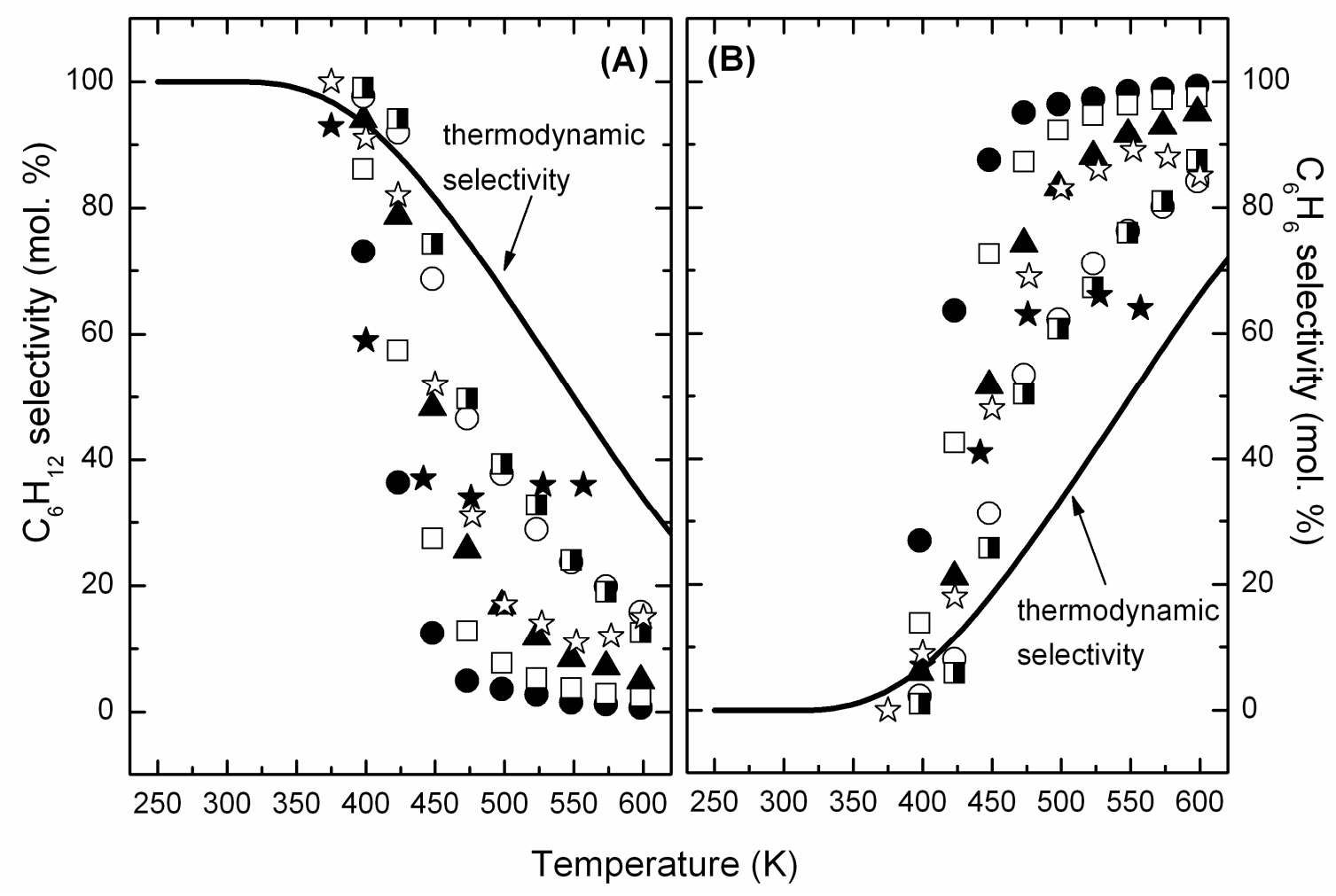

Figure A1. The selectivity to (A) cyclohexane and (B) benzene over a number of catalysts: (,) $3.2 \% \mathrm{Pt}(1 \mathrm{~nm}) / \mathrm{SiO}_{2} ;(\forall) 0.6 \% \mathrm{Pt}(1.7 \mathrm{~nm}) / \mathrm{SBA}-15 ;(7) 0.77 \% \mathrm{Pt} /(2.9 \mathrm{~nm}) / \mathrm{SBA}-15 ;(-) 0.6 \%$ $\mathrm{Pt}(3.6 \mathrm{~nm}) / \mathrm{SBA}-15$; and ()) $0.62 \% \mathrm{Pt}(7.1 \mathrm{~nm}) / \mathrm{SBA}-15$, ( $\xi) \operatorname{Pt}(111)$ and $(\psi) \operatorname{Pt}(100)$ single crystal surfaces [9]. The solid line represents the thermodynamic selectivity, based on the temperature dependent Gibbs free energy $\left(\Delta \mathrm{G}_{\mathrm{rxn}}(\mathrm{T})\right)$ of both hydrogenation and dehydrogenation reactions [41]. The points in (A) that lie above the thermodynamic selectivity represent typical uncertainties in the rate measurements, while the points in (B) lie above the thermodynamic selectivity line because the decreased hydrogenation rate leads to a selectivity in benzene greater than that predicted by thermodynamics. The reaction conditions were 10 Torr $\mathrm{C}_{6} \mathrm{H}_{10}, 200 \mathrm{H}_{2}$ Torr and the temperature stated on the $x$-axis. 